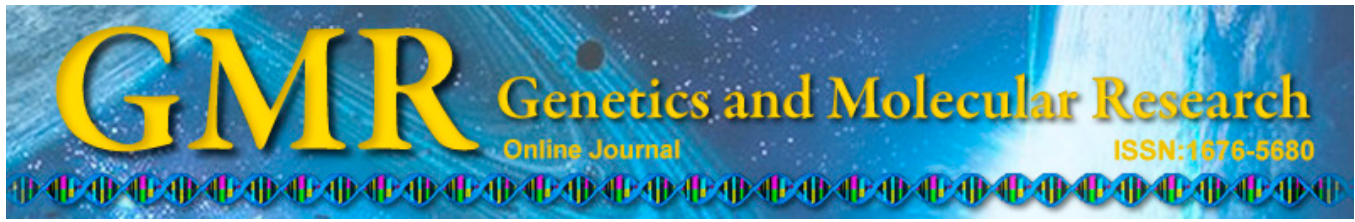

\title{
Selection of sugar cane full-sib families using mixed models and ISSR markers
}

\author{
L.M. Almeida ${ }^{1}$, A.P. Viana ${ }^{1}$, G.M. Gonçalves ${ }^{2}$ and G.C. Entringer ${ }^{1}$ \\ ${ }^{1}$ Laboratório de Melhoramento Genético Vegetal, \\ Centro de Ciências e Tecnologias Agropecuárias, \\ Universidade Estadual do Norte Fluminense Darcy Ribeiro, \\ Campos dos Goytacazes, RJ, Brasil \\ ${ }^{2}$ Petrobras-Biocombustível, Rio de Janeiro, RJ, Brasil \\ Corresponding author: A.P. Viana \\ E-mail: pirapora@uenf.br
}

Genet. Mol. Res. 13 (4): 9202-9212 (2014)

Received October 9, 2013

Accepted June 21, 2014

Published November 7, 2014

DOI http://dx.doi.org/10.4238/2014.November.7.7

\begin{abstract}
In 2006, an experiment examining families belonging to the first selection stage of the Sugar Cane Breeding Program of Universidade Federal Rural do Rio de Janeiro/Rede Interuniversitária para o Desenvolvimento do Setor Sucroalcooleiro was conducted. Families and plants within families were evaluated to select superior plants for subsequent stages of the breeding program. The experiment was arranged in a randomized block design, in which progenies were grouped into 4 sets, each with 4 replicates and 100 seedlings per plot. The following traits were evaluated: average stem diameter, total plot weight, number of stems, Brix of the lower stem, and Brix of the upper stem. The study of families used the restricted maximum likelihood/best linear unbiased procedure mixed models. After selection, families were genotyped via inter-simple sequence repeat to assess the genetic distance of genotypes. This approach was found to be efficient for selecting new genotypes.
\end{abstract}

Key words: Inter-simple sequence repeat; Selection of families;

Restricted maximum likelihood/best linear unbiased procedure; Sugar cane 


\section{INTRODUCTION}

Sugar cane is a very important species cultivated in the tropics and subtropics and plays a significant economic and environmental role in Brazil, occupying a total area of 8.527 million hectares in the agricultural years 2011-2012. A total volume of 596,630.20 million tons of sugar cane was processed in the sugar and alcohol sector, and 72.83 million tons was used to manufacture of "cachaça" and animal feed, obtain seeds, and other uses according to data from the Companhia Nacional de Abastecimento (Conab, 2012) (National Supply Company).

Sugar cane breeding programs evaluate a large number of clones each year in different harvests, seasons, and regions. It has become increasingly difficult to select the best genotypes based on phenotype. Thus, accurate methods of statistical analysis are necessary to ensure greater reliability in the selection process.

In the early stages of sugar cane selection, mass selection is used to select plants (seedlings) only by phenotype. This is the most widely used method because of its simple operation. However, it is less efficient than selecting by families (Barbosa et al., 2004).

Breeding programs are dynamic, with changes proposed and tested to improve the efficiency of the selection process and facilitate assessment. Thus, researchers have proposed new selection methods, such as incorporating recurrent selection and selection of families using mixed models.

Selection of families is an alternative method for improving the efficiency of mass selection in sugar cane. The use of families increases the probability of identifying superior clones, thereby improving the efficiency using available resources to facilitate sugar cane breeding programs (Barbosa et al., 2005a).

In this type of evaluation, superior families and individuals within each family are selected. Thus, families can be evaluated in trials with replication, whose plots are composed of individuals that have not been cloned (seedlings). This method can provide information regarding the genetic value of the families assessed. When performed in families with higher genotypic values, selection may increase the probability of identifying superior clones in their respective progenies. The restricted maximum likelihood (REML)/best linear unbiased procedure (BLUP) mixed models has been used to estimate genetic parameters and predict the genotypic values of sugar cane families by analyzing individuals within families (Resende and Barbosa, 2006).

In this context and in association with the selection process, estimating genetic diversity using DNA markers is important for breeding, as crosses involving parents that produced genetically divergent families are better suited to produce a high heterotic effect and greater genetic variability of segregant populations.

Thus, molecular biology techniques have emerged as tools that are useful for the early and accurate identification of individuals with a better combination of favorable alleles. The general trend of plant breeding involves the use of classical techniques with modern molecular biology techniques, as both show advantages and limitations.

Choosing a molecular marker technique depends on its reproducibility and simplicity. The molecular marker technique inter-simple sequence repeat (ISSR) was developed in 1994 (Zietkiewicz et al., 1994). ISSRs are semi-random markers that are amplified by polymerase chain reaction (PCR) in the presence of an oligonucleotide complementary to a particular microsatellite. 
This type of molecular marker has various applications in plant breeding, including studies on genetic diversity, phylogeny, gene mapping, and fingerprinting, among others, in various cultures (Kantety et al., 1995; Ajibade et al., 2000; Bornet et al., 2001).

ISSR is a PCR-based marker that has some advantages over other markers. Amplification requires no succession information regarding the genome or from highly polymorphic standards (Zietkiewicz et al., 1994). Each band corresponds to a DNA sequence delimited by 2 inverted microsatellites. Additionally, ISSR target sequences are abundant throughout the genome of eukaryotes and evolve rapidly (Esselman et al., 1999). Thus, ISSRs are useful within populations of genetic studies, particularly in clonal detection, diversity, and identification of closely related individuals (Salimath et al., 1995; de Oliveira et al., 1996).

Therefore, we selected the best families and individuals within families under evaluation at stage T1 of Rede Interuniversitária para o Desenvolvimento do Setor Sucroalcooleiro/ Universidade Federal Rural do Rio de Janeiro breeding program, estimated the genetic divergence of the best families, and monitored the best parents involved in the crosses.

\section{MATERIAL AND METHODS}

In February 2006, an essay was installed in the area of the Plant Disa, in the municipality of Conceição da Barra-ES and included families belonging to the 1st selection stage (T1) of the Sugar Cane Breeding Program of Universidade Federal Rural do Rio de Janeiro/ Rede Interuniversitária para o Desenvolvimento do Setor Sucroalcooleiro (Inter-University Network for the Development of Sugar and Alcohol Industry), in partnership with Universidade Estadual do Norte Fluminense Darcy Ribeiro.

Families used in this study were sampled from crosses carried out at the Experimental Station of Serra do Ouro in the municipality of Murici, State of Alagoas, from where samples were collected from 68 biparental (full-sib) crosses.

The assay included 68 families and 3 standard cultivars and was arranged in sets in a randomized block design. Progenies and controls (treatments) were grouped into 4 sets of treatment groups, each with 4 replications and 100 seedlings per plot, with $0.50 \mathrm{~m}$ between plants and $1.40 \mathrm{~m}$ between rows.

Cane cutting was conducted in 2007, and no evaluations were performed. All assessments of families and plants within families were carried out during the 1st and 2nd ratoons in 2008 and 2009, both between and within families (individuals from each family were phenotyped).

At harvest, the average stem diameter was measured using a caliper. The readings were carried out in the center of the internode, located in the average length of the stem; 5 random readings were taken by observation (seedling) and considering the average value. Average stem diameter was measured in both agricultural years (2008 and 2009). Total soluble solid context, known as Brix (\%), was determined using a field refractometer to conduct 5 random measurements and the average value was determined. Measurements were made at the lower stem (Brix PE) and upper stem (Brix PT). Both traits were measured in both agricultural years (2008 and 2009). Stem weight (P) was measured in kilograms by weighing all stems present in all lines of the plot using a dynamometer. This trait was measured only in the 1st year (2008). The total number of stems (NC): was counted in the clumps analyzed. This trait was measured only in the 2nd agricultural year (2009).

Phenotypic evaluations were carried out using the Selegen-REML/BLUP software system, using the individual BLUP for the mixed model: $Y=X r+Z g+W p+e$, where: $y=$ 
data vector, $r=$ vector of repetition effects (assumed to be fixed) added to the overall average; $g=$ vector of individual genotypic effects (assumed to be random); $p=$ vector of effects of plot; and $e=$ errors or residues (random). The capital letters refer to the matrices of incidence for these purposes. The following variance components were estimated: $V_{\mathrm{g}}$ : genotypic variance between the progenies of full-sibs, equivalent to 0.5 of the additive genetic variance plus 0.25 of the genetic variance of dominance, neglecting epistasis; $V_{\text {parc }}$ : environmental variance between plots; $V_{\text {within }}$ : residual variance within plot; $V_{\mathrm{f}}$ : individual phenotypic variance; $h^{2}{ }_{\mathrm{a}}=\mathrm{h}^{2}$ : individual heritability, obtained by ignoring the fraction 0.25 of the genetic variance of dominance; $c^{2}{ }_{\text {parc }}=\mathrm{c}^{2}$ : coefficient of determination of the effects of the plot; $h_{\mathrm{mp}}^{2}$ : heritability of the average progeny, assuming complete survival; Acprog: accuracy of the selection of progenies, assuming complete survival; $h_{\text {ad }}^{2}$ : additive heritability within the plot, obtained by ignoring the fraction 0.25 of the dominance genetic variance and overall average of the experiment.

Genetic diversity among the selected families was examined out to investigate the degree of diversity of the sugar cane materials routinely used in crosses in sugar cane breeding programs to identify crosses between genetically distant parents, seek increased heterosis, and identify superior clones.

We selected 39 individuals analyzed by mixed models methodology, derived from 14 best families, and those genotypes were used for genetic diversity analysis by ISSR molecular markers.

Approximately $100 \mathrm{mg}$ macerated tissue was transferred to $1.5 \mathrm{~mL}$ tubes and immersed in liquid $\mathrm{N}_{2}$ for DNA extraction according to the DNeasy Plant Mini Kit (Qiagen) protocol: $400 \mathrm{~mL}$ extraction buffer 1 (GP1 Buffer) and $5 \mathrm{~mL} 10 \mathrm{mg} / \mathrm{mL}$ RNase were added to the tubes containing the samples and were mixed by vortexing. Samples were incubated at $65^{\circ} \mathrm{C}$ for 10 $\mathrm{min}$. The tube was inverted every 5 min during incubation. Next, $100 \mathrm{~mL}$ buffer 2 (buffer GP2) was added to the solution and the tubes were vortexed to obtain a homogeneous mixture. After incubating the microtubes on ice for $3 \mathrm{~min}$, approximately $500 \mathrm{~mL}$ sample was transferred to a new tube with a filter column in a $2 \mathrm{~mL}$ collection tube. This material was centrifuged for $3 \mathrm{~min}$ at 13,000 rpm. The filter column was discarded and the supernatant was carefully transferred to a new tube. Next, $750 \mathrm{~mL}$ buffer 3 (GP3 buffer containing isopropanol) was added to the filtrate (product of cell lysis) and immediately mixed by vortexing for $5 \mathrm{~s}$. The entire mixture was transferred to a matrix column placed in a collection tube. Centrifugation was performed at 13,000 rpm for $2 \mathrm{~min}$. The filtered material remaining in the collection tube was discarded.

After adding $500 \mathrm{~mL}$ wash buffer containing ethanol to the column, centrifugation was performed at 13,000 rpm for $30 \mathrm{~s}$. The filtrate was discarded and the previous step was repeated. The matrix column was transferred to a $1.5 \mathrm{~mL}$ tube and $100 \mathrm{~mL}$ preheated elution buffer was added to the center of the matrix column. The material was incubated for 5 min until the elution buffer had been absorbed by the matrix. Centrifugation was performed at 13,000 rpm for $30 \mathrm{~s}$ to elute the purified DNA.

PCR reactions were performed on a Veriti 384-well Thermal Cycler (Applied Biosystems, Foster City, CA, USA) with initial denaturation for $4 \mathrm{~min}$ at $94^{\circ} \mathrm{C}$ followed by 45 cycles of amplification, including $94^{\circ} \mathrm{C}$ for 1 min, $44^{\circ}-50^{\circ} \mathrm{C}$ for 1 min, and $72^{\circ} \mathrm{C}$ for $3 \mathrm{~min}$. A final extension step was performed at $72^{\circ} \mathrm{C}$ for $7 \mathrm{~min}$. Each PCR reaction contained $10 \mathrm{ng}$ DNA, $0.5 \mu \mathrm{M}$ primer, $0.5 \mathrm{U}$ Taq DNA polymerase, 0.02 $\mathrm{mM}$ dNTPs, and $1.5 \mathrm{mM} \mathrm{MgCl} 2 \mathrm{PCR}$ buffer (1X). Ultrapure water was added to increase the final reaction volume to $13 \mu \mathrm{L}$.

The samples were analyzed by $1.0 \%$ agarose gel electrophoresis and stained using a mixture of Blue Juice 6x with Gel Red at a 1:1 ratio to determine the DNA concentration. A DNA stan- 
dard sample that contained a known concentration of phage $\lambda$ DNA (10, 20, 30, 50, and $100 \mathrm{ng})$.

Ultraviolet light (Fotodocumentador MiniBis, DNR Pro-Bio-Imaging Systems, Jerusalem, Israel) was used for visualization. The concentration of the bands was determined using an image program with a marker of 250 base pairs (bp) used as a standard. Subsequently, the DNA was diluted to $5 \mathrm{ng} / \mu \mathrm{L}$ and stored at $20^{\circ} \mathrm{C}$ until PCR.

Cluster analysis between genotypes was carried out using the arithmetic complement of the Jaccard index as a measure of dissimilarity and the Ward method as a clustering technique. The distance matrix based on the arithmetic of the Jaccard index was used to cluster genotypes by the Ward method. The results were analyzed using the Genes software system (Viçosa, MG, Brazil) (Cruz, 2013).

\section{RESULTS AND DISCUSSION}

An important step in sugar cane (Saccharum spp) breeding is the early stage, known as T1. During this stage, thousands of heterozygous individuals from hybridizations between previously selected parents are produced (Gilbert et al., 2006). Selection of families may be preferable during this stage when it is carried out based on low individual heritability.

In family studies, analysis of traits with low heritability indicated that $75-80 \%$ of phenotypic variation can be explained by genetic factors (Gilbert et al., 2006).

When selection is carried out in families with high genotypic values, the probability of identifying superior clones in their respective progenies is increased (Resende and Barbosa, 2006).

Table 1 presents the genetic parameters estimated by REML/BLUP in the study of 68 full-sib families of sugar cane.

Table 1. Estimates of variance components (individual REML) and genetic parameters for the following variables: diameter, number of stems, Brix PE, and Brix PT from 68 full-sib families of sugar cane.

\begin{tabular}{|c|c|c|c|c|c|c|c|c|c|c|}
\hline \multirow[t]{2}{*}{ Trait } & \multicolumn{10}{|c|}{ Genetic parameters } \\
\hline & $V_{g}^{1 /}$ & $V_{\text {parc }}$ & $V_{\text {within }}$ & $V_{f}$ & $h_{a}^{2}$ & $C_{\text {parc }}^{2}$ & $h_{m p}^{2}$ & Acprog & $h^{2}{ }_{a d}$ & Average \\
\hline$\overline{\mathrm{DMC}}$ & 0.60 & 0.60 & 7.71 & 8.92 & 0.14 & 0.07 & 0.60 & 0.78 & 0.08 & 24.6 \\
\hline $\mathrm{NC}$ & 2.51 & 2.51 & 37.97 & 42.9 & 0.12 & 0.06 & 0.58 & 0.76 & 0.07 & 14.4 \\
\hline Brix PE & 0.37 & 0.37 & 3.19 & 3.92 & 0.19 & 0.09 & 0.64 & 0.80 & 0.11 & 20.95 \\
\hline Brix PT & 0.49 & 0.49 & 4.46 & 5.45 & 0.18 & 0.09 & 0.64 & 0.79 & 0.11 & 19.04 \\
\hline
\end{tabular}

$V_{g}^{1 /}=$ genotypic variance between full-sib progenies, equivalent to 0.5 of the additive genetic variance plus 0.25 of the dominance genetic variance, disregarding epistasis; $V_{\text {parc }}=$ environmental variance between plots; $V_{\text {within }}=$ residual variance within the plot; $V_{f}=$ individual phenotypic variance; $h^{2}{ }_{a}$ and $h^{2}=$ narrow sense individual heritability, achieved by disregarding the fraction 0.25 of the genotypic variance of dominance; $c^{2}$ parc and $c^{2}=$ coefficient of determination of the effects of the plot; $h^{2}=$ heritability of the average of progenies, assuming full survival; Acprog $=$ accuracy of the selection of progenies, assuming full survival; $h^{2}{ }_{a d}=$ additive heritability within the plot, achieved by disregarding the fraction 0.25 of the genotypic variance of dominance and the overall average of the experiment.

When individual selection, also known as mass selection, was compared to family selection, the selective efficiency was lower for all traits analyzed, as their respective individual heritabilities $\left(h^{2}\right)$ were lower than the heritability estimates for the family average $\left(h^{2}{ }_{m p}\right)$. The traits showed average values for average progeny heritability, such as 0.58 for $\mathrm{CN}, 0.60$ for average stem diameter, and 0.64 for Brix PE and PT, yielding high accuracies for selection from superior families based on these selection traits $(0.78,0.76,0.80$, and 0.79 , respectively) (Table 1$)$.

In the identification of promising families with high Brix values, it was observed that selection between families $\left(h_{m p}^{2}=0.64\right)$ was effective, as this method allowed for a selective 
accuracy between families of $80 \%$ in the present study.

Selecting new genotypes of sugar cane with high Brix values is very important. Tables 2 and 3 show the following values: phenotypic (f), genotypic $(\mathrm{g})$, predicted genotypic $(\mathrm{u}+\mathrm{g})$, selection gain (\%), and new averages of the 14 full-sib families evaluated and selected in this study for the traits Brix PE and Brix PT, respectively.

Table 2. Ordination of the 14 full-sib families of sugar cane selected based on average components for the Brix $\mathrm{PE}$ trait and its following values: phenotypic (f), genotypic $(\mathrm{g})$, predicted genotypic values $(\mathrm{u}+\mathrm{g})$, selection gain $(\%)$, and new averages.

\begin{tabular}{rcccccccc}
\hline Order & Block & Family & Individual & $\mathrm{f}$ & $\mathrm{g}$ & $\mathrm{u}+\mathrm{g}$ & Gain & New average \\
\hline 1 & 1 & 20 & 2 & 25.00 & 1.1101 & 22.0658 & 1.1101 & 22.0658 \\
2 & 2 & 20 & 1 & 24.00 & 1.0510 & 22.0067 & 1.0806 & 22.0362 \\
3 & 2 & 20 & 4 & 24.00 & 1.0510 & 22.0067 & 1.0707 & 22.0264 \\
4 & 3 & 20 & 3 & 23.00 & 0.9722 & 21.9278 & 1.0461 & 22.0018 \\
5 & 3 & 20 & 10 & 23.00 & 0.9722 & 21.9278 & 1.0313 & 21.9870 \\
6 & 2 & 27 & 9 & 24.40 & 0.9655 & 21.9212 & 1.0203 & 21.9760 \\
7 & 3 & 60 & 4 & 24.00 & 0.9571 & 21.9127 & 1.0113 & 21.9670 \\
8 & 1 & 20 & 3 & 24.00 & 0.9499 & 21.9055 & 1.0036 & 21.9593 \\
9 & 2 & 60 & 2 & 24.20 & 0.9077 & 21.8634 & 0.9930 & 21.9486 \\
10 & 1 & 19 & 8 & 25.00 & 0.9043 & 21.8599 & 0.9841 & 21.9398 \\
11 & 2 & 61 & 1 & 24.40 & 0.8838 & 21.8395 & 0.9750 & 21.9306 \\
12 & 2 & 60 & 4 & 24.00 & 0.8757 & 21.8313 & 0.9667 & 21.9224 \\
13 & 3 & 60 & 1 & 23.40 & 0.8609 & 21.8166 & 0.9586 & 21.9142 \\
14 & 3 & 23 & 2 & 24.00 & 0.8554 & 21.8111 & 0.9512 & 21.9069 \\
15 & 3 & 12 & 1 & 24.40 & 0.8331 & 21.7888 & 0.9433 & 21.8990 \\
16 & 1 & 27 & 8 & 24.20 & 0.8323 & 21.7880 & 0.9364 & 21.8920 \\
17 & 3 & 20 & 7 & 22.00 & 0.8119 & 21.7676 & 0.9291 & 21.8847 \\
18 & 2 & 20 & 2 & 22.50 & 0.8106 & 21.7663 & 0.9225 & 21.8781 \\
19 & 2 & 27 & 3 & 23.40 & 0.8053 & 21.7609 & 0.9163 & 21.8720 \\
20 & 2 & 27 & 6 & 23.40 & 0.8053 & 21.7609 & 0.9108 & 21.8664 \\
21 & 1 & 20 & 1 & 23.00 & 0.7896 & 21.7453 & 0.9050 & 21.8607 \\
23 & 3 & 19 & 1 & 23.00 & 0.7663 & 21.7220 & 0.8934 & 21.8491 \\
26 & 3 & 24 & 7 & 23.20 & 0.7503 & 21.7060 & 0.8779 & 21.8335 \\
\hline
\end{tabular}

Table 3. Ordination of the 14 sugar cane full-sib families, selected based on the average components for the Brix PT trait and its following values: phenotypic (f), genotypic $(\mathrm{g})$, predicted genotypic $(\mathrm{u}+\mathrm{g})$, selection gain $(\%)$, and new averages.

\begin{tabular}{ccccccccc}
\hline Order & Block & Family & Individual & $\mathrm{f}$ & $\mathrm{g}$ & $\mathrm{u}+\mathrm{g}$ & Gain & New average \\
\hline 1 & 2 & 61 & 8 & 28.00 & 1.6339 & 20.6800 & 1.6339 & 20.6800 \\
2 & 2 & 60 & 4 & 23.80 & 1.2679 & 20.3140 & 1.4509 & 20.4970 \\
3 & 2 & 47 & 1 & 23.00 & 1.1590 & 20.2051 & 1.3536 & 20.3997 \\
4 & 3 & 60 & 1 & 22.60 & 1.1330 & 20.1791 & 1.2985 & 20.3445 \\
5 & 1 & 16 & 1 & 24.40 & 1.0531 & 20.0992 & 1.2494 & 20.2955 \\
6 & 1 & 60 & 3 & 23.00 & 1.0476 & 20.0937 & 1.2200 & 20.2600 \\
7 & 1 & 16 & 6 & 24.20 & 1.0220 & 20.0681 & 1.1880 & 20.2340 \\
8 & 3 & 19 & 1 & 22.80 & 1.0212 & 20.0672 & 1.1670 & 20.2100 \\
9 & 3 & 60 & 6 & 21.80 & 1.0089 & 20.0550 & 1.1496 & 20.1957 \\
10 & 2 & 47 & 2 & 22.00 & 1.0038 & 20.0499 & 1.1350 & 20.1800 \\
11 & 2 & 24 & 7 & 22.50 & 0.9969 & 20.0430 & 1.1225 & 20.1686 \\
12 & 1 & 25 & 8 & 24.20 & 0.9889 & 20.0349 & 1.1114 & 20.1574 \\
13 & 1 & 60 & 2 & 22.60 & 0.9856 & 20.0316 & 1.1017 & 20.1478 \\
14 & 3 & 8 & 3 & 22.40 & 0.9744 & 20.0205 & 1.0926 & 20.1387 \\
15 & 3 & 8 & 6 & 22.40 & 0.9744 & 20.0205 & 1.0847 & 20.1308 \\
16 & 1 & 19 & 8 & 23.40 & 0.9668 & 20.0129 & 1.0773 & 20.1234 \\
17 & 3 & 24 & 7 & 21.80 & 0.9397 & 19.9857 & 1.0692 & 20.1153 \\
18 & 3 & 47 & 1 & 21.20 & 0.9311 & 19.9772 & 1.0616 & 20.1076 \\
19 & 1 & 47 & 2 & 22.00 & 0.9077 & 19.9538 & 1.0535 & 20.0995 \\
20 & 3 & 47 & 7 & 21.00 & 0.9000 & 19.9461 & 1.0458 & 20.0919 \\
21 & 3 & 38 & 8 & 22.40 & 0.8851 & 19.9311 & 1.0381 & 20.0842 \\
\hline
\end{tabular}


All individuals from the 14 families evaluated presented genotypic values above the experimental average (Brix $\mathrm{PE}=20.95$ and Brix $\mathrm{PT}=19.04)$. This indicates a high probability of identifying new promising genotypes for cane yield per hectare within these best families.

An alternative method for exploring the potential of these families may include to plant more seedlings from the families, and later conduct individual selection based on a particular trait (Resende and Barbosa, 2006).

Family 20 (RB 945961 x RB 957751) contained the most selected individuals and showed the highest values for the Brix PE trait. The following families had high Brix PT values: 60 (RB 855463 x SP 83-2847), 47 (L 60-14 x SP 80-3280), and 61 (RB 835486 x RB 955970), showing the highest phenotypic value.

Thus, it is important to explore crosses with higher genotypic values to identify potential clones with a higher probability of high sugar cane production. Exploiting superior families will allow for more potential clones to be used in subsequent stages of the sugar cane breeding program (Barbosa et al., 2005a, Resende and Barbosa 2006).

Resende and Barbosa (2006) developed the stimulated individual BLUP method and reported that the selection of individuals within families must consider the genotypic value of families, such that a greater number of potential clones would be selected from the best families.

No families with genotypic values for the Brix trait below the overall average were identified in this study. To increase selection efficiency, families with genotypic values below the experimental average were discarded because of the low probability of selecting promising clones as described by Resende and Barbosa (2006).

It is also important to perform further studies of family selection to identify the interaction between superior families and between various selection environments because interaction between families and environments is likely to occur (Gilbert et al., 2006).

Therefore, selecting families with genotypic values above the experimental average provided significant gains for the Brix PE and PT traits. The 4 families showing the highest values for this trait were: 20 (RB 945961 x RB 957751), 60 (RB 855463 x SP 83-2847), 47 (L 60-14 x SP 80-3280), and 61 (RB 835486 x RB 955970).

Selecting families using REML/BLUP mixed models is an important strategy for identifying families with high genotypic values and increases the probability of selecting potential clones.

Thirty-nine individuals with higher values for the Brix PE and Brix PT traits were selected using the REM/BLUP method with the ISSR molecular technique to investigate the genetic variability among the 68 full-sib families of sugar cane belonging to the 1st selection stage (T1). Twenty-three primers were used, generating a total of 193 bands, 17 of which were monomorphic and 176 were polymorphic. The average number of bands per primer was 8.40. The estimated average percentage of polymorphism was $90.38 \%$. The primer with the highest number of polymorphic bands and amplified fragments was $(\mathrm{GA})_{8} \mathrm{CTT}$, which was observed in a total of 15 fragments (Table 4).

According to Ajibade et al. (2000), 7-30 primers, which generate 50-200 polymorphic bands, are sufficient for estimating genetic relationships within and between species. Kantety et al. (1995) used 10 primers and obtained a polymorphism rate of $95 \%$, with 54 polymorphic bands in populations of Zea mays. Almeida et al. (2009) obtained a total of 56 bands for sugar cane, with an average of 7 bands per primer. Fifty-three bands (95\%) were polymorphic. 
Table 4. List of primers used and number of polymorphic amplified fragments and ISSR oligonucleotides.

\begin{tabular}{|c|c|c|c|c|c|}
\hline Oligonucleotides & Crops & $\mathrm{AT}\left({ }^{\circ} \mathrm{C}\right)$ & Amplified fragments & Polymorphic fragments & Percentage of polymorphism \\
\hline$(\mathrm{AG})_{8} \mathrm{C}$ & Sugar cane & 50 & 08 & 07 & 87.50 \\
\hline$(\mathrm{AG})_{8}^{6} \mathrm{~T}$ & Sugar cane & 50 & 09 & 08 & 88.89 \\
\hline$(\mathrm{GGGTG})_{3}$ & Sugar cane & 44 & 06 & 05 & 83.33 \\
\hline$(\mathrm{GGAT})_{3}{ }^{3}$ & Sugar cane & 44 & 03 & 03 & 100.0 \\
\hline$(\mathrm{AC})_{8} \mathrm{CTT}$ & Sugar cane & 45 & 14 & 14 & 100.0 \\
\hline$(\mathrm{TC})_{8}^{8} \mathrm{AGA}$ & Sugar cane & 45 & 11 & 10 & 90.90 \\
\hline$(\mathrm{GT}){ }_{8}^{8} \mathrm{CTC}$ & Sugar cane & 46 & 10 & 09 & 90.0 \\
\hline (CT) ${ }_{8} \mathrm{AGG}$ & Sugar cane & 46 & 12 & 12 & 100.0 \\
\hline$(\mathrm{GA})_{8}^{8} \mathrm{CTT}$ & Sugar cane & 50 & 16 & 15 & 93.75 \\
\hline (TC) ${ }_{8} \mathrm{AGG}$ & Sugar cane & 50 & 10 & 09 & 90.0 \\
\hline$(\mathrm{AG})_{8}^{8} \mathrm{CTA}$ & Sugar cane & 44 & 14 & 14 & 100.0 \\
\hline$(\mathrm{GACA})_{4}$ & Sugar cane & 45 & 07 & 06 & 85.71 \\
\hline$(\mathrm{GA})_{8} \mathrm{C}^{4}$ & Elephant-grass & 44 & 07 & 06 & 85.71 \\
\hline$(\mathrm{GA})_{8}^{\mathrm{T}} \mathrm{T}$ & Elephant-grass & 50 & 09 & 09 & 100.0 \\
\hline$(\mathrm{ATC})_{6} \mathrm{C}$ & Elephant-grass & 50 & 08 & 07 & 87.50 \\
\hline$(\mathrm{ATG})_{6}^{\circ} \mathrm{G}$ & Elephant-grass & 50 & 10 & 08 & 80.0 \\
\hline $\mathrm{G}(\mathrm{CTA})_{6}$ & Elephant-grass & 44 & 07 & 06 & 85.71 \\
\hline$(\mathrm{ACC}) \mathrm{Y}^{6}$ & Elephant-grass & 44 & 05 & 05 & 100.0 \\
\hline$(\mathrm{GATA})_{4}$ & Elephant-grass & 44 & 06 & 05 & 83.33 \\
\hline$(\mathrm{GA})_{6} \mathrm{CC}$ & Stevia & 44 & 04 & 04 & 100.0 \\
\hline$(\mathrm{CT})_{8} \mathrm{G}$ & Sweet potato & 46 & 07 & 05 & 71.43 \\
\hline$(\mathrm{AC})_{8} \mathrm{~T}$ & Sweet potato & 46 & 04 & 03 & 75.0 \\
\hline$(\mathrm{AG})_{8} \mathrm{YA}$ & Sweet potato & 46 & 06 & 06 & 100.0 \\
\hline TOTAL & - & 46 & 193 & 176 & 2078.76 \\
\hline Average & - & & 8.40 & 7.65 & 90.38 \\
\hline
\end{tabular}

$\mathrm{AT}=$ annealing temperature.

The distance matrix between individuals was achieved based on the bands observed using the arithmetic complement of the Jaccard index and cluster analysis using the Ward method. The results obtained by the group containing 39 individuals allowed for the sorting these individuals into 6 distinct groups (Table 5 and Figure 1).

Cluster analysis joins sample units into groups using a given classification criterion, so that there is homogeneity within the group or heterogeneity between groups.

Table 5. Grouping of 39 sugar cane individuals selected by mixed models using the Ward method, based on 176 ISSR polymorphic fragments, using the arithmetic complement of the Jaccard index.

\begin{tabular}{ll}
\hline Groups & Individuals \\
\hline I & $39,33,34,31,32,36,38,35,37$ \\
II & $15,17,19,16,20,14,18$ \\
III & $5,4,6,7,1,2,3$ \\
IV & $25,27,26,28$ \\
V & $29,30,21,22,11,10,13$ \\
VI & $8,9,24,12,23$ \\
\hline
\end{tabular}

Group 1 contained genotypes 39 (family 47, individual 2), 33 (family 47, individual 2), 34 (family 16, individual 1), 31 (family 20, individual 1), 32 (family 20, individual 3), 36 (family 20, individual 2), 38 (family 20, individual 1), 35 (family 61, individual 1), and 37 (family 27, individual 9).

Group 2 contained genotypes 15 (family 60, individual 1), 17 (family 25, individual 8), 19 (family 47, individual 1), 16 (family 24, individual 7), 20 (family 24, individual 7), 14 (family 12, individual 1), and 18 (family 61, individual 8). 


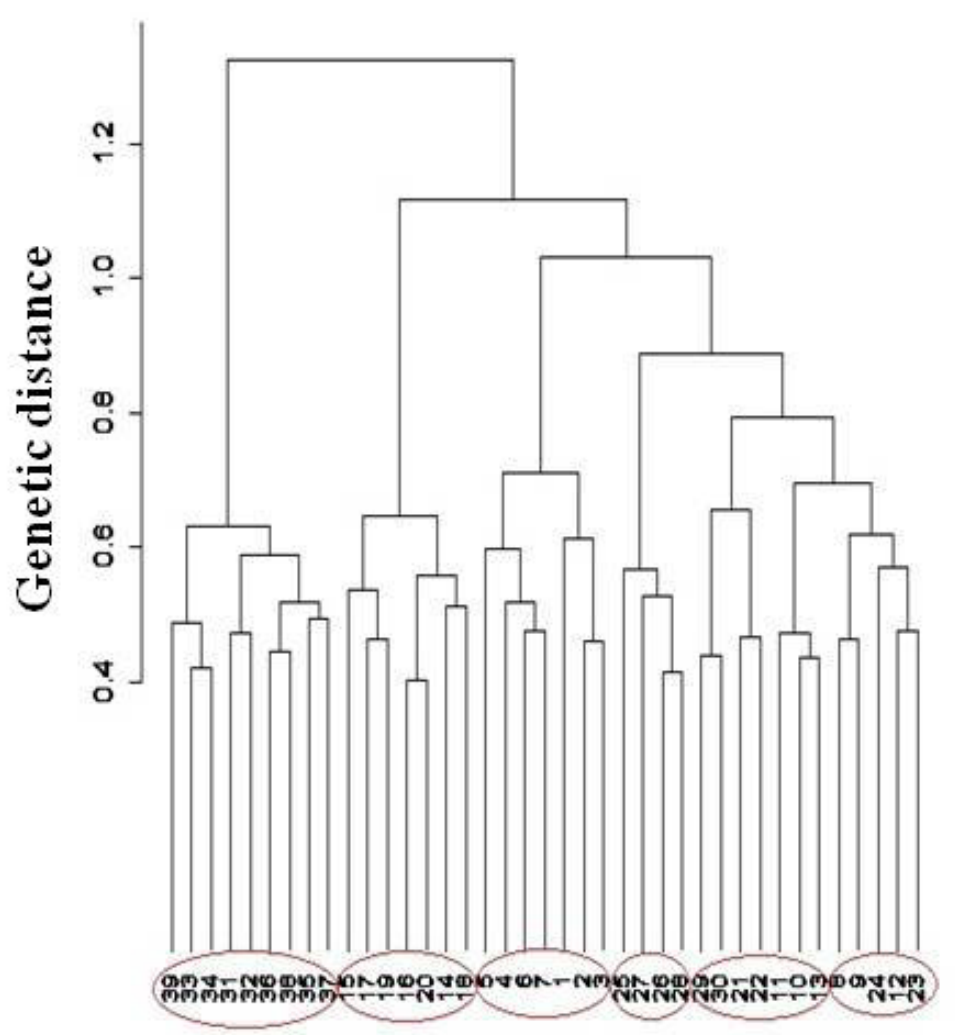

Figure 1. Dendrogram obtained using the WARD hierarchical method of 39 individuals of full-sib families selected by mixed models, using the arithmetic complement of the Jaccard index as a dissimilarity measure.

Group 3 was formed by genotypes 5 (family 47, individual 7), 4 (family 60, individual 6), 6 (family 47, individual 1), 7 (family 60, individual 2), 1 (family 8, individual 3), 2 (family 20 , individual 10), 3 (family 38 , individual 8 ).

Group 4 was composed of genotypes 25 (family 19, individual 8), 27 (family 16, individual 6), 26 (family 60 , individual 4), and 28 (family 60 , individual 3 ).

Group 5 included genotypes 29 (family 20, individual 2), 30 (family 20, individual 4), 21 (family 20, individual 7), 22 (family 8, individual 6), 11 (family 60, individual 4), 10 (family 20, individual 3), and 13 (family 19, individual 1).

Group 6 was composed of genotypes 8 (family 60, individual 2), 9 (family 27, individual 3), 24 (family 27, individual 8), 12 (family 27, individual 6), and 23 (family 23, individual 2).

The most divergent genotypes were number 5 (group 3, family 47, individual 7), and 24 (group 6, family 27, individual 8), with a distance of 0.75 . Additionally, the most similar genotypes, with a distance of 0.40 , were number 16 (group 2, family 24, individual 7, block 2 ) and 20 (group 2, family 24 , individual 7 , block 3 ). Given the greatest distance (0.75), the accessions for this value were considered in different groups and, considering the shortest distance $(0.40)$, the genotypes for this value are arranged in the same group. 
Determining the genetic distance between genotypes in a population of interest is important for breeding programs because it favors the organization of the germplasm and more efficient genotype sampling (Nienhuis et al., 1993).

Genetic distance values can be estimated using molecular markers and/or agronomic (morphologic) traits. In the first case, there is no influence from the environment.

Pearson's linear correlation coefficient between elements of the dissimilarity matrix (matrix of distances between cultivars, obtained from the original data) and the cophenetic matrix elements (matrix of distances between cultivars, obtained from the dendrogram) is known as the cophenetic correlation coefficient. This coefficient can be used to evaluate the consistency of the clustering standard of hierarchical clustering methods. Values close to unity indicate better representation (Cruz and Carneiro, 2003).

The cophenetic correlation coefficient for this analysis was 0.75 . There is variability in the consistency of the clustering standard, obtained from the arithmetic complement of the Jaccard index and cluster analysis by Ward method, as it is a selection assay belonging to the 1 st selection stage when individuals are still segregant. Therefore, additional evaluation of the selected families can be carried out to assess the most divergent parents used to obtain crosses. These crosses may be further potentialized by allocating a larger number of segregating plants for phenotyping, which will increase the probability of selecting promising clones for the program under development.

\section{REFERENCES}

Ajibade SR, Weeden NF and Chite SM (2000). Inter simple sequence repeat analysis relationships in the genus Vigna. Euphytica 111: 47-55.

Almeida CMA, Lima SN, Lima GSA and Brito JZ (2009). Caracterização molecular de cultivares de cana-de-açúcar utilizando marcadores ISSR. Cienc. Agrotecnol. 33.

Barbosa MHP, Resende MD, Peternelli LA, Bressiani JA, et al. (2004). Use of REML/BLUP for the selection of sugarcane families specialized in biomass production. Crop Breed. Appl. Biotechnol. 4: 218-226.

Barbosa MHP, Resende MD, Silveira LCI and Peternelli LA (2005). Estratégias de Melhoramento Genético da Canade-Açúcar em Universidades. In: IX Simpósio Sobre Seleção Recorrente. Universidade Federal de Lavras, Lavras.

Bornet B and Branchard M (2001). Nonanchored inter simple sequence repeat (ISSR) markers: Reproducible and specific tolls for genome fingerprinting. Plant Mol. Biol. 19: 209-215.

CONAB (Companhia Nacional de Abastecimento) (2012). Acompanhamento da Safra Brasileira Cana-de-Açúcar. Safra 2011/12, Brasília. Available at [www.conab.gov.br] Accessed September 29, 2012.

Cruz CD and Carneiro PCS (2003). Modelos Biométricos Aplicados ao Melhoramento Genético. Universidade Federal de Viçosa, Viçosa.

Cruz CD (2013). GENES - a software package for analysis in experimental statistics and quantitative genetics. Acta Sci. Agronomy 35: 271-276.

de Oliveira AC, Richter T and Bennetzen JL (1996). Regional and racial specificities in sorghum germplasm assessed with DNA markers. Genome 39: 579-587.

Esselman EJ, Jianqiang L, Crawford DJ, Winduss JL, et al. (1999). Clonal diversity in the rare Calamagrostis porteri ssp. Insperata (Poaceae): comparative results for allozymes and random amplified polymorphic DNA (RAPD) and inter simple sequence repeat (ISSR) markers. Mol. Ecol. 8: 443-451.

Gilbert RA, Shine Junior JM, Miller JD, Rice RW, et al. (2006). The effect of genotype, environment and time of harvest on sugarcane yields in Florida, USA. Field Crops Res. 95: 156-170.

Kantety RV, Zeng X, Bennetzen JL and Zehr B (1995). Assessment of genetic diversity in dent and popcorn (Zea mays L.) inbred lines using inter-simple sequence repeat (ISSR) amplification. Mol. Breed. 1: 365-373.

Nienhuis J, Slocum MK, DeVos DA and Muren R (1993). Genetic similarity among Brassica oleracea genotypes as measured by restriction fragment length polymorphisms. J. Am. Hort. Sci. 118: 298-303.

Resende MDV and Barbosa MHP (2006). Selection via simulated individual BLUP base on family genotypic effects in sugarcane. Pesq. Agropec. Bras. 41: 421-429. 
Salimath SS, de Oliveira AC, Godwin ID and Bennetzen JL (1995). Assessment of genome origins and genetic diversity in the genus Eleusine with DNA markers. Genome 38: 757-763.

Zietkiewicz E, Rafalski A and Labuda D (1994). Genome fingerprinting by simple sequence repeat (SSR)-anchored polymerase chain reaction amplification. Genomics 20: 176-183. 